\title{
Taking What a Language Gives Us: The Reported Inclusive/ Exclusive Distinction in Maya-Mam ${ }^{1}$
}

\author{
WESLEY COLLINS \\ SIL International; Universidad Ricardo Palma, Lima, Peru
}

\section{Introduction}

Mam is a Mayan language spoken by upwards of 700,000 people in Guatemala's Western Highlands. Data for this paper were elicited from speakers in the town of Comitancillo, San Marcos, a major town in the Central Mam area. I also cite data from Northern Mam, centered in the department of Huehuetenango, and I allude to data from Tacaneco (Western) Mam. In this paper I compare the Mam possessive paradigm as instantiated by speakers from these areas and I discuss some of the paradigm's morphological implications.

It has long been advanced that Maya-Mam possessives encode an inclusive/exclusive distinction for first person plural (England 1983; Ortiz Maldonado 2004), but that, otherwise, the possessive paradigm lines up with Spanish or English with basically first, second, and third person distinctions in both singular and plural forms. See Table 1 in (1) below, based on the obligatorily possessed stem -xjalil ' 'people'.

(1)

Table 1: Possessive paradigm, Northern Mam; adapted from Ortiz Maldonado (2004:86)

\begin{tabular}{|l|l|l|l|l|l|}
\hline & & & 1P.IN & q-xjalil & 'our IN people \\
\hline 1S & n-xjalil-a & 'my people' & 1P.EX & q-xjalil-a & 'our EX people \\
\hline 2S & t-xjalil-a & 'your people' & 2P & ky-xjalil-a & 'you all's people' \\
\hline 3S & t-xjalil & 'his/her people' & 3P & ky-xjalil & 'their people' \\
\hline
\end{tabular}

\footnotetext{
${ }^{1}$ Thanks to Thomas Godfrey, David Odden, Steve Marlett, and David Weber for comments on early drafts of this paper. Of course, any oversights and errors in analysis are my own.

${ }^{2}$ Data are written in practical orthography. Assume Spanish pronunciation except that $k y$ and $q$ are palatal and uvular stops; $x$ and $j$ are retroflexed and uvular fricatives. $T x$ is a retroflexed affricate. Stops and affricates followed by ' are glottalized, and glottal stop is indicated by '. In this article, the dash is used only to separate morphemes within the possessive forms being considered.
} 


\section{The Inclusive/Exclusive Distinction}

Many languages grammaticalize the distinction between first person plural inclusive and exclusive. For example, if I talk to my wife about our honeymoon, she's included in the event, whereas if I talk to you about our honeymoon, you are excluded. In English this is vague - grammatically if not semantically-whereas in Mam, and many other languages, particularly Austronesian and Dravidian languages, and Amerindian languages like Quechua and Mam, the difference is coded.

We can see that, aside from the stem itself, the possessive forms all have a prefix - either $n$ - or $t$ - for singular forms, or $q$ - or $k y$ - for plural forms. In addition, first and second singular and first person plural exclusive and second person plural also have an enclitic $-a$.

About these possessive forms, England, says: Nouns "are inflected for possession using a set of prefixes and accompanying enclitics" (1983:66, emphasis WMC).

Maldonado Andrés, et al. say, "Possessed nouns are indicated by means of a set of prefixes and enclitics which together refer to grammatical person and number of the possessor" (1986:xxv, emphasis and translation from Spanish, WMC).

According to Feliciano and Jiguan, these clitics are "a group of elements that complete the pronouns and follow the possessed nouns" (2002:30-31, emphasis and translation from Spanish, WMC).

Under each of these analyses the $-a$ clitic is part of the unit of possessive morphology, that is, it is part and parcel of the affixal forms for first and second person singular, first person plural exclusive, and second person plural, and apparently inseparable from them. In other words, third person singular forms are marked with a prefix only, as are first person plural inclusive and third person plural, whereas the remaining forms are marked by a discontinuous affix comprised of both a prefix and the $-a$ enclitic.

What we see portrayed, then, in (1), is a basic first, second, third person singular and plural paradigm, similar to Spanish or English, but with the addition of the inclusive/exclusive distinction in first person plural.

This analysis works in the sense that it maintains a distinction among the seven attested possessive forms by means of the interaction of the four prefixes and the presence or absence of the clitic. On the other hand, it doesn't provide for any interesting generalizations about the use or function of the enclitic $-a$ nor of the prefixes themselves. This is unfortunate, since it seems that there is more at play in these data than simply seven distinct grammatical items, both in terms of the prefixes as well as the appearance, or not, of the clitic.

\section{An Alternative Analysis}

I suggest a different analysis based on data from Comitancillo, where, by my reckoning, the clitic does not merely accompany the prefixes, but its occurrences are essentially independent of them. 
(2)

Table 2: Possessive paradigm in Central Mam

\begin{tabular}{|l|l|l|l|l|l|}
\hline 1S.IN & n-xjalil & 'my IN people' & 1P.IN & q-xjalil & $\begin{array}{l}\text { 'our IN } \\
\text { people }\end{array}$ \\
\hline 1S.EX & n-xjalil-a & 'my EX people & 1P.EX & q-xjalil-a & $\begin{array}{l}\text { 'our EX } \\
\text { people }\end{array}$ \\
\hline 2S & t-xjalil-a & 'your people' & 2P & ky-xjalil-a & $\begin{array}{l}\text { 'you all's } \\
\text { people' }\end{array}$ \\
\hline $3 \mathrm{~S}$ & t-xjalil & 'his/her people' & 3P & ky-xjalil & $\begin{array}{l}\text { 'their } \\
\text { people' }\end{array}$ \\
\hline
\end{tabular}

Note that the Comitancillo data in (2) correspond exactly with the Ixtahuacán data in (1) except for the additional first person singular form at the top left of the table, a form I'm presently calling first person singular inclusive. This form nicely fills in the paradigm, much like fitting the final puzzle piece in its place.

Interestingly, the additional form $n$-xjalil, selects from the same inventory of prefixal and clitic forms as the other members of the paradigm instantiated in both (1) and (2). In other words, $n$-xjalil doesn't simply fit the paradigm, it seems to belong there. The paradigm in (2) vis-à-vis (1) gives rise to several questions: What do the prefixes and the clitic mean? Do they simply mark person and number as England and Maldonado Andrés et al. suggest, or could they be coding something more? Are the prefixes and the clitic interdependent as claimed by proponents of the traditional analysis, or are they largely independent, as I claim they are in the Comitancillo data? And does the Comitancillo data help us understand what's going on in the Ixtahuacán data, or perhaps even in the larger Mam area?

In Mam, when people talk about 'my anything', they normally exclude the interlocutor - my house, my book, and my brother are all mine, not yours. And if a Mam school teacher is speaking to me, and wants to say something about her indigenous students and their families, she would call them n-xjalil-a 'my people - not yours'. This would be true for both Ixtahuacán and Comitancillo speakers. Indeed, this is the only first person form attested in the Ixtahuacán data in (1). However, were a school teacher in Comitancillo to address her own people at a town meeting, she could say, as in sentence (3):

Ayi'y n-xjalil, noq same, o'kx kab'e tal yol kxel nq'ma'n kye'y.

My people, excuse me, I have just a few words to address to you.

The absence of the enclitic $-a$ in the form $n$-xjalil in (3) codes that the people are included in some way in the possession - even though it's a singular form. Whereas first person singular $n$-xjalil-a codes 'my people, not yours', n-xjalil codes 'my people - including you', or 'my people, which are also your people'. In other words, Comitancillo first person singular inclusive and exclusive possessive 
forms pattern just like the inclusive and exclusive marking on first person plural forms.

These first person inclusive forms are common in direct address: $N-k$ ' $w a l$ 'my child', said by a man addressing his son or daughter, $n$-chmil 'my husband', said by a woman addressing her husband, w-erman (a borrowing from Spanish hermano 'sibling') used to address 'my brother or my sister', usually in a religious context (initial $w$ - is an allomorph of $n$ - which occurs before vowel initial roots or stems). Interestingly, this first person singular inclusive form can also be extended to non-humans, or even non-sentient addressees as with $n$-chej 'my horse', $n$-ja 'my house', or $n$-tx'otx', 'my land', where in (4) I address my land in a kind of soliloquy. Compare sentences (4) and (5).

(4) Ay, n-tx'otx', k'u'jlinxix wu'n, jun t-ky'iwb'il q-Man wi'ja,

My beloved land (note lack of clitic $-a$ in $n$-tx'otx'), you are a blessing of our Father to me.

Ajo lo n-tx'otx'-a.

This is my land (note word final $-a$ ), 'my land, not yours'.

From these facts, it appears that for Comitancillo, we clearly have some kind of inclusive-exclusive distinction in 1st person singular as well as in 1 st person plural.

If we ignore the clitics (for now) and just look at the prefixes in (2) above, we have a two by two grid with first person in the top half of the table and non-first person in the bottom half, and with singular forms to the left and plurals to the right. There is a two-way distinction between singular and plural and, likewise, a two-way distinction of person - first person and non-first person — not a three-way distinction.

Now consider the final $-a$, the clitic. In the first person singular and first person plural forms in (2) above, it appears that the clitic codes exclusivity, as discussed previously. The forms unmarked with the clitic appear to code inclusivity. The rub with committing to the clitic as a marker of exclusivity is what to make of the second person forms, i.e. the clitic's co-occurrence with the $t$ - and $k y$ prefixes: singular t-xjalil-a 'your people' versus t-xjalil 'his or her people', as well as with the plural forms: ky-xjalil-a 'you all's people' versus $k y$-xjalil 'their people'. If the clitic is indeed a marker of exclusivity, who is being excluded in the non-first person forms?

So at first blush, it seems that in first person, both singular and plural, the clitic distinguishes exclusive from inclusive forms, while in the non-first person forms, it distinguishes traditional second from third person. In other words, the clitic does double duty. England (1976:260) acknowledges the notion of the disparate functions of the clitic, saying: "The enclitics on the first-person forms indicate absence of second person, while the enclitics on the remaining forms indicate presence of second person". Nevertheless, the traditional analysis wisely 
rejects this split personality for the clitic. Why have what appears to be the same form doing two different things in very similar morphological contexts-one time, distinguishing inclusive from exclusive and another time distinguishing second person from third in both singular and plural? In order to avoid this, proponents of the traditional analysis atomize the entire possessive paradigm and conclude that each form is different from every other one based on the interplay of the four prefixes and the single clitic, just as if they had totally differently phonological shapes, as in English: my, your, our, their, etc. This is basically what Maldonado Andrés et al. claim above - that the prefixes and clitic together refer to grammatical person and number of the possessor. What this leaves us with are seven different unrelated forms, in (1) - or eight forms in (2). By this analysis, the prefixes and clitic are interdependent, together distinguishing person and number, nothing else.

The traditional analysis can account for the data, even the additional first person singular form in (2), but it does so by ignoring the categories that the language itself presents. Looking at those forms in (2) which include the clitic, I suggest, following Godfrey (1981), that what the clitic encodes is not exclusivity but rather the lack of solidarity between the interlocutor and the speaker. This may sound like a rose by any other name (that 'lack of solidarity' is just another name for exclusivity), but it nicely solves an interesting problem, the seemingly disparate functions of the same clitic in the first person and non-first person forms.

What the language gives us data-wise, then, is a two by two by two matrix of person, number, and solidarity between speaker and hearer. To discuss this matrix, I will first tease it apart, beginning with Table 3 in (6) below.

(6)

Table 3: Comitancillo Mam singular possessor inflectional marking ${ }^{3}$

\begin{tabular}{l|l|l|}
\multicolumn{1}{c}{$\mathrm{n}-$} & \multicolumn{1}{l}{$\mathrm{t}-$} \\
\cline { 2 - 3 }$-\varnothing$ & $\begin{array}{l}\mathrm{Sp} \Lambda \mathrm{H} \\
(1 \mathrm{~S} . \mathrm{IN})\end{array}$ & $\begin{array}{l}\sim \mathrm{Sp} \Lambda \sim \mathrm{H} \\
(3 \mathrm{~S})\end{array}$ \\
\cline { 2 - 3 }$-\mathrm{a}$ & $\begin{array}{l}\mathrm{Sp} \Lambda \sim \mathrm{H} \\
(1 \mathrm{~S} . \mathrm{EX})\end{array}$ & $\begin{array}{l}\sim \mathrm{Sp} \Lambda \mathrm{H} \\
(2 \mathrm{~S})\end{array}$ \\
\hline
\end{tabular}

To understand the table in (6), begin at the left, which shows those forms prefixed with $n$ - 'first person singular'. The top left box has no clitic and therefore codes solidarity between singular speaker and hearer. Speaker is possessor and

\footnotetext{
${ }^{3}$ Abbreviations used in this paper are minimal: $\mathrm{S}$ singular, $\mathrm{P}$ plural, IN inclusive, EX exclusive, Sp speaker, and $\mathrm{H}$ hearer.
} 
speaker and hearer are both involved in the possession, or, as formalized, both speaker and hearer, or, roughly, what I'm presently calling 'first person singular inclusive'.

The bottom left box includes both the first person singular prefix $n$ - and the clitic $-a$ which marks unequal involvement or lack of solidarity between speaker and hearer, or, more formally, speaker and not hearer, or, roughly, 'first person singular exclusive'.

The second column shows those forms prefixed with $t$ - 'non-first person singular.' The top right box has no clitic and therefore codes solidarity between speaker and hearer: neither speaker nor hearer; in other words, 'third person singular'.

The bottom right box has both the non-first person singular prefix $t$ - and the clitic $-a$ which marks lack of speaker-hearer solidarity, or not speaker but hearer. This codes traditional second person singular. The plural paradigm in (7) works in exactly the same way, substituting only the plural prefixes for the singular ones in (6).

Table 4: Comitancillo Mam plural possessor inflectional marking

\begin{tabular}{c|l|l|}
\multicolumn{1}{c}{ q- } & \multicolumn{1}{l}{ ky- } \\
\cline { 2 - 3 }$-\varnothing$ & $\begin{array}{l}\mathrm{Sp} \Lambda \mathrm{H} \\
(1 \mathrm{P} . \mathrm{IN})\end{array}$ & $\begin{array}{l}\sim \mathrm{Sp} \Lambda \sim \mathrm{H} \\
(3 \mathrm{P})\end{array}$ \\
\cline { 2 - 3 }$-\mathrm{a}$ & $\begin{array}{l}\mathrm{Sp} \Lambda \sim \mathrm{H} \\
(1 \mathrm{P} . \mathrm{EX})\end{array}$ & $\begin{array}{l}\sim \mathrm{Sp} \Lambda \mathrm{H} \\
(2 \mathrm{P})\end{array}$ \\
\hline
\end{tabular}

\section{Possessives as Deictic Forms}

All pronominal forms are deictic in nature, possessives included. Pronouns and other deictic forms are indicators or pointers, which are relative to and grounded in the extra-linguistic context-terms like here and there, now and then, I and you, and, for the present focus-my and your-which have no specific reference aside from the context of speech. Deictic forms take their meaning from the moment of utterance and the participation schemes involved in direct speech. Who the word $I$ references, depends upon who is speaking.

The physical context of utterance requires a deictic center or origo, a center stake from which all deictic notions are calculated, historically considered to be ego- or speaker-centric. As Fillmore suggests:

I carry around with me, everywhere I go, my own private world. The spatial centre of this world is my location...the temporal centre of this world is the passing moment of my consciousness...the social centre of this world is me" (1998:40-41). 
Lyons restates this even more succinctly, saying: "The canonical situation-ofutterance is egocentric" (1977:638).

\section{Ego-centrism and Socio-centrism}

The matrix for Mam possessive prefixes is indeed egocentric in its coding. The $n$ codes the speaker as the singular possessor, the $t$ - codes other-than-speaker as the singular possessor. The prefixes give us two options for person, not three: 'my' or 'not my', a coding of quintessential egocentricity. The clitic, on the other hand, calls upon speaker solidarity with the interlocutor. Whereas the prefixes $n$ - and $t$ emerge from a binary, egocentric notion of origo, the clitic depends on a sociocentric origo (Hanks 1990). It codes interlocutor solidarity with the speaker. In other words, the clitic operates independently of the prefixes in the sense that its meaning is orthogonal to the meaning of the prefixes.

This analysis give us a two by two by two matrix which codes the interaction of participants of the socio-center, most basically, a speaker and a hearer. The paradigm provides coding for singular or not, involvement or not of the speaker as possessor, and solidarity or not of the speaker and hearer. Number is orthogonal to the deictic center, but our other two categories, speaker involvement and speakerhearer solidarity, are not. I've suggested that the marking of speaker involvement by means of prefixes, codes egocentrism. Either I own it or I don't. Hearer solidarity with the speaker is marked by the presence or absence of the clitic. This codes for the socio-center of both speaker and hearer, not simply the ego-center of speaker alone. With this notion of socio-centricity and the terms socio-center and socio-centric, I follow Hanks 1990.

The strength of this analysis' two by two by two array is that it is based on the data as they appear, not as we overlay them with a first, second, and third person paradigm from outside the language itself. The matrix gives us 2 cubed or eight possibilities - all of which are attested in the Comitancillo data, and only one of which is not attested in the Ixtahuacán data. ${ }^{4} \mathrm{We}$ 've only looked at a single noun. There are three basic noun classes in Comitancillo Mam, all of which exhibit the same preoccupation with both the ego- and the socio-center-and all of which are subject to the two by two by two matrix. Although the paradigm is fuller in Comitancillo than in the north, the same analysis will work for both.

Hanks, in opposition to Fillmore and Lyons, claims that egocentricity is not the right way to ground the deictic field, that the deictic center isn't egocentric - a bubble around the speaker, a center from which all deictic notions find their place. Rather, for Hanks, the deictic center is socio-centric - a bubble around a speaker and his or her interlocutor(s). And these interlocutors and all significant others get situated inside or outside of the bubble by means of the very act of speaking. Our

\footnotetext{
${ }^{4}$ Actually, the 'missing form', $n$-xjalil, is indeed attested in Ixtahuacán, but it does not belong to the same paradigm as the other forms in (1). Rather it is used for contrastive emphasis (England, 1983:143), and only to code lack of solidarity. In this contrastive emphasis structure, lack of the clitic, then, does not code speaker-hearer solidarity. Rather, the entire construction codes contrastive (lack of solidarity) emphasis. See citation for discussion.
} 
Mam data adduce additional evidence to Hanks' claim since solidarity between members of the socio-center-minimally a speaker and a hearer, is the unmarked case in the use or not of the clitic. Lack of solidarity is the marked form among members of the socio-center.

Yet even for Hanks, socio-centricity can be overruled. The socio-center of speaker-and-interlocutor as origo can itself become a contested space and conversation can degenerate into a ping-pong match of egocentric moves between speaker and interlocutor.

It appears that our Mam data actually encode both aspects of this sense of centeredness-ego-centrism and socio-centrism. As we've seen, the prefixes are speaker-centric. Certainly they assume a socio-center with an interlocutor, as per Hanks, since the notion of $I$ means nothing unless there is a non- $I$ against which $I$ exists. This is the figure-ground relationship implied within Hanks' view of the deictic center. Nevertheless, the actual coding of possession is strictly speaker oriented. Something is either mine or not mine, ours or not ours.

The clitic, however, codes solidarity between speaker and hearer. Its presence or absence does not merely assume an interlocutor, it crucially codes for her or him. This strengthens the evidence for Hanks' notion of the deictic center being not just a single individual speaker, but a twosome (or more) of culturally competent actors. Mam then recognizes and codes both the notion of an ego-center and a socio-center.

The importance of these possessive forms is that they are actually the Mam instantiation of Mayan Set A ergative markers that code not only possessives, but also the agent of transitive verbs and, in relative clauses, both the agent and the object of transitives as in (8), as well as the subject of intransitives.

T-aj-a tu'n t-kub' ky-b'inchin jun ti'.

You want them to do something.

With $t-a j-a$ 'you want', we have both the $t$ - prefix and the clitic. As with the possessives, the $t$ - codes non-first person singular, while the - $a$ clitic marks lack of solidarity between interlocutor and speaker. This means 'you'. The $t$ - prefix of $t$ $k u b$ ' cross-references the non-first person singular object. Lack of the clitic codes solidarity between speaker and hearer, or traditional third person, 'something'. And the $k y$ - prefix of $k y$-b'inchin marks plural non-first person. With no clitic, it codes solidarity with first person-both speaker(s) and interlocutors are not involved, leaving traditional 'third person plural'.

Not only are the set A markers used far beyond just possession, as I mentioned in the previous paragraph, but the same clitic also functions with Set B absolutive markers as well, where it again codes lack of solidarity with speaker (as it does with Set A markers) while in a morphotactic context where Set A prefixes are not found at all. This is further evidence of the independence of the clitic from the Set A prefixes. 


\section{Mam Possessives in a Wider Context}

England (1976:259-260) suggests that the Mam enclitic derives from a second person honorific marker still extant in Aguacatec, a Mamean language. In short, the precursor of Aguacatec third person prefixal forms $t$ - and $k y$-plus the enclitic $-u$ ' became polite second person forms. Mam has lost this honorific sense, while maintaining the clitic for second person forms.

Since Mamean languages are the only Mayan languages to use these clitics in conjunction with other affixes to code person, England suggests that the cliticized forms are innovative. It is unclear whether the clitics on first person forms developed from these honorifics or separately. Nor is it clear what the second person clitics may have meant in their "post-honorific" stages. It was perhaps at this point that this post-honorific clitic was reanalyzed as an indicator of lack of solidarity between speaker and hearer.

Godfrey (1981:9) points out that for Tacanec (Western) Mam, the clitics are all different in each of their four occurrences. Nevertheless, they are each realized as either a vowel or vowel plus glottal stop, and they are used in a way corresponding exactly to the same paradigm as the Ixtahuacán data in (1).

England surmises (p.c.) that the fact that the Tacanec clitics are all different supports the notion that the clitics don't presently - and therefore did not historically_mean the same thing (as I claim they do now for the Comitancillo data). Of course, if we assume that these clitics derived from the same Aguacatec honorific clitic, $-u$ ', we don't know how nor why the Tacanec clitics differentiated into four distinct forms. If the single clitic is the historical base, and if it was sufficient, together with the possessive prefixes to distinguish all persons, why did it differentiate further into four clitics? In response, Godfrey (p.c.) claims that the Tacanec clitics are different from each other because they agree with four different person/number markers. But they do more than just repeat information. They also specify lack of solidarity between speaker and hearer. He suggests that in other Mam variants, the clitics have collapsed to a single form because the repetition of information was unnecessary, having been handled by our two by two by two matrix.

It is also possible that the unusual semantics of a first person singular inclusive form makes such a form likely to be dropped, due to its being overwhelmed by the far more common 'my, not your' forms. Under this analysis, the Comitancillo version of the paradigm is conservative, with the first person singular solidarity forms having been part of the grammars of other Mam dialects, but subsequently lost due to lack of use.

In any event, how the system has come to be what it is is irrelevant to present day speakers who in their daily speech habits care not about diachrony, but synchrony. I believe that the data presented here most clearly support the meanings for both the prefixes and the presence or absence of the present-day clitic, as I've described in this paper. 
Wesley M. Collins

\section{Ethnosysntax}

What do we make of all this? It seems that the language is giving us what I've been calling the two by two by two matrix, which lays out for us, in binary fashion, the three categories I've outlined in this paper: speaker involvement in possession, or not; number (singular or plural), and solidarity between the speaker and hearer, or not. These categories have not so much been applied to the data as they have emerged from it, based on the notion that what looks similar morphologically should be assumed to be similar unless we can show that the forms are indeed divergent. The $t$ - prefix marks the same thing on all forms-non-first person, not two things, second and third person. In the same way, the presence or absence of the clitic marks the same thing-interlocutor solidarity (or lack thereof) with the speaker - not two things: exclusivity and person.

Mam speakers must deal with both ego-centricity and socio-centricity, phenomena which impose a way of thinking upon speakers of the language. This is reminiscent of Slobin's idea of "thinking for speaking" (1996), where a language's obligatory categories (like tense, number, and person in English or Spanish - but not evidentiality or duality - for example, which don't exist in these languages as grammatical categories) must be taken into account before one can speak at all. Mam speakers not only identify participants in conversation, coding self and non-self, singular and plural. They also code solidarity with the hearer, as the hearer is distinguished as participating equally or not with the speaker in the matter at hand.

I have suggested elsewhere (Collins 2005) the importance of a sense of center-or balance about such a center-to speakers of Mam in the conception and practice of daily life, particularly in terms of health and illness etiology; the constructed world of patios and plazas; and religion and cosmology. It may well be that this very notion of centeredness as a cultural theme, or what Gossen (1986:5) calls a "symbol cluster" is the cultural analogue of a grammatical theme, where the sense of a grammatical center grounds deictic notions such as pronominal reference, Mam's complex and ubiquitous directional verbs and auxiliaries, and other origo-dependent grammatical features. These types of recurrent grammatical features are what Hale calls a "lexico-semantic...motif which functions as an integral component in a grammar" (1986:234). Sapir described such interrelated grammatical features as "the genius of the language" (1920:120).

Enfield suggests in his book, Ethnosyntax (2002), that language and culture are not only connected, but "interconstitutive, through overlap and interplay between people's cultural practices and preoccupations and the grammatical structures they habitually employ" (2002:3-4). To that end, he further suggests that "it is well worth exploring the idea that a language's morphosyntactic resources are related to the cultural knowledge, attitudes, and practices of its speakers" (2002:24), or, as Duranti claims, language "both presupposes and brings about ways of being in the world (1997:1). Language, then, both reflects the culture of its speakers while at the same time standing as the most pervasive and effective mechanism in the acculturation of a society's members. 


\section{Conclusion}

To do the exploration that Enfield envisions, and that Sapir describes, we need to look at a language on its own terms and by means of its own terms, not by means of categories and paradigms comfortable to us and which fit the data of the languages we know. In a field where we are rightly intrigued with what is similar about the languages of the world, we must also remember that each language stands alone in contrast to all others by means of its own genius.

We may yet find it easiest to continue to refer to the different Mam possessive forms as first, second, and third person, inclusive and exclusive, singular and plural. Perhaps this is inevitable as we try to understand Mam in terms of what we know about other languages. But if we look at Mam in its own terms, we see different nuances - and a different genius - from that of English and Spanish.

\section{References}

Collins, Wesley M. 2005. Centeredness as a Cultural and Grammatical Theme in Maya-Mam. Ph.D. diss., The Ohio State University.

Enfield, Nick J. 2002. Ethnosyntax: Explorations in Grammar and Culture. Oxford: Oxford University Press.

England, Nora C. 1976. The Development of the Mam Person System. International Journal of American Linguistics 42(3):259-261.

England, Nora C. 1978. Space as a Mam Grammatical Theme. In Nora C. England, ed., Papers in Mayan linguistics, 225-38. Columbia, MO: University of Missouri Press.

England, Nora C. 1983. A Grammar of Mam, a Mayan Language. Austin: University of Texas Press.

Feliciano Pérez, Jesús Eberardo and Saturnino Jiguan Berdúo. 2002. Tumel Qyol Mam [Grammar of Mam]. San Marcos, Guatemala: Jefatura Departamental de Educación Bilingüe Intercultural.

Fillmore, Charles J. 1997. Lectures on Deixis. Stanford: CSLI Publications.

Godfrey, Thomas James. 1981. Grammatical Categories for Spatial Reference in the Western Mam Dialect of Tacaná. Ph.D. diss., University of Texas at Austin.

Gossen, Gary. 1986. Mesoamerican Ideas as a Foundation for Regional Synthesis. In Gary Gossen, ed., Symbol and Meaning Beyond the Closed Community: Essays in Mesoamerican Ideas, 1-8. Albany: Institute for Mesoamerican Studies Press.

Hale, Kenneth L. 1986. Notes on World View and Semantic Categories: Some Walpiri Examples. In Pieter Muysken and Henk van Riemsdijk, eds., Features and Projections, 233-54. Dorcrecht: Foris Publications.

Hanks, William F. 1990. Referential Practice: Language and Lived Space among the Maya. Chicago: University of Chicago Press. 
Lyons, John. 1977. Semantics, Volume 2. Cambridge: Cambridge University Press.

Maldonado Andrés, Juan, Juan Ordóñez Domingo and Juan Ortiz Domingo. 1986. Diccionario Mam. Guatemala: Universidad Rafael Landívar.

Ortiz Maldonado, Marco Antonio. 2004. Nuky'b'il ttxolilyol Mam [Descriptive Grammar of the Mam Language], San Pedro Sacatepéquez, San Marcos, Guatemala: Academia de Lenguas Mayas de Guatemala.

Sapir, Edward. 1921. Language. New York: Harcourt, Brace and Company.

Slobin, Dan. 1996. From "Thought and Language" to "Thinking for Speaking". In John J. Gumperz and Stephen C. Levinson, eds., Rethinking Linguistic Relativity, 70-96. Cambridge: Cambridge University Press.

Wesley M. Collins

CILTA

Casilla Postal 112

Calle Artesanos 150, Int. \#151

Lima 33, Peru

wes_collins@sil.org 